\title{
Magnetic Resonance Imaging Role in the Differentiation Between Atypical Cartilaginous Tumors and High-Grade Chondrosarcoma: An Updated Systematic Review
}

\author{
Salah M. Alhumaid ${ }^{1}$, Alwaleed Alharbi IV ${ }^{1}$, Hamad Aljubair ${ }^{1}$ \\ 1. Department of Diagnostic Radiology, Prince Sultan Military Medical City, Riyadh, SAU
}

Corresponding author: Alwaleed Alharbi IV, alwaleed-ksa@hotmail.com

\begin{abstract}
Chondrosarcoma (CS) is a malignant tumor affecting the bones while atypical cartilaginous tumors (ACTs) are chondral tumors with moderate cellularity, mild atypia, and with myxoid changes and mild metastatic ability. Both can have one of the worst prognoses if not identified early enough. Magnetic resonance imaging (MRI) has been one of the modalities to detect such tumors and we aim to determine the common characteristic and features to be seen while screening for CS or ACTs. We conducted a systematic review of the previously published reports that investigated the diagnostic ability of MRI and the reported characteristics that can differentiate between ACTs and high-grade chondrosarcomas (HGCS). A comprehensive relevant database search was performed to include all the relevant studies. Among these studies, seven studies investigated the overall accuracy in the classification of the different chondroma types. Additionally, many studies reported the characteristic findings of each tumor according to the MRI results. These characteristics mainly included trapped fat, bone marrow edema, cortical damage, and softtissue expansion. Therefore, further attention should be given to these criteria for better assessment, differentiation, and favorable outcomes. MRI can efficiently identify some of the characteristics of both ACTs and HGCS. However, combining it with other radiological modalities may lead to a better differentiation. The detection of ACTs and HGCS lesions with MRI solely has been doubted before in the literature.
\end{abstract}

Review began 10/16/2020 Review ended 10/20/2020 Published 10/29/2020

(c) Copyright 2020 Alhumaid et al. This is an open access article distributed under the terms of the Creative Commons Attribution License CC-BY 4.0., which permits unrestricted use, distribution, and reproduction in any medium, provided the original author and source are credited.
Categories: Radiology, Oncology

Keywords: mri imaging, chondroid tumors, chondrosarcoma, high-grade chondrosarcoma, atypical cartilaginous, tumors

\section{Introduction And Background}

Chondrosarcoma (CS) is a malignant tumor that primarily affects bones. It is one of the most common tumors in this field following osteosarcoma and multiple myelomas and was first described in 1939 by Lichtenstein and Jaffe $[1,2]$. The main feature of this tumor is that it has a high tendency to produce cartilages where it commonly occurs in long bones as a central CS form. Furthermore, the histological nature of this tumor shows that it can be classified into three grades based on the cell; mitosis, cellularity, and atypia [3]. The three grades from one to three are classified according to their degree of malignancy as low, intermediate, and high. The incidence of CS is one per 200,000 per year with a rate of $30 \%$ for chondrosarcoma grade one (CS1), which is considered a non-metastatic low-grade tumor, but a locally aggressive one $[4,5]$. Although being local, this form of CS is usually treated by surgical removal followed by palliative radiotherapy as the biopsy is considered hazardous due to the high index of wrong sampling [6]. However, other non-surgical approaches have been introduced as successful alternatives. These include intralesional curettage together with the application of local adjuvant therapy $[7,8]$. Cartilaginous lesions of unknown malignant potential have been commonly used to describe atypical cartilaginous tumors grade 1 (ACTs1), and are usually used to describe chondral tumors with moderate cellularity, mild atypia, myxoid changes, and mild metastatic ability [9].

Overall, CS possesses a poor prognosis in general due to the potential ability to fail locally [10]. Furthermore, another form that is usually associated with a low-grade form is the dedifferentiated CS, which is a highly malignant sarcoma with no cartilage formation [11-14]. The other two grades of CS can metastasize as it has been previously reported in up to $30 \%$ of grade two (intermediate form) while it can reach up to $70 \%$ in grade three (highly malignant form) [15]. The differentiation between the grades of CS is of high importance due to the different prognosis of each grade, and therefore, each grade will have a specific therapeutic and follow-up approach [16-18]. The therapeutic approaches for these tumors, unlike CS1 or ACTs, are amputation or endoprosthetic reconstruction together with the application of the limb salvage technique [19].

Recently, the incidence of this tumor has rapidly increased and is usually discovered accidentally due to the high frequency of performing magnetic resonance imaging (MRI) in patients having bone or joint-related problems $[20,21]$. Therefore, MRI utilization is considered better for the detection and differentiation of 
such tumors. However, the diagnosis of this tumor is made on a bifactorial level by clinical findings as well as the results of the widely used imaging approaches. The majority of investigations reporting the efficacy of MRIs to differentiate such tumors have also focused on differentiating enchondroma (EC), which is the benign form of cartilaginous tumors, and grade one CS [22-24]. Moreover, identification of the different characteristics of ACTs on MRIs can be challenging as many studies have demonstrated many characteristics. Therefore, in this study, we aim to systematically review the efficiency of MRIs similar to what Deckers et al. [25] did previously but in a more systematic and characteristic approach, as well as added additional studies and content that was not included in that study, to differentiate between the different types of CS and identify the imaging criteria found in such imaging technique.

\section{Review}

\section{Search strategy, data collection, and study selection}

Following a predefined protocol, collection of the relevant studies was performed through the Preferred Reporting Items for Systematic Reviews and Meta-Analyses (PRISMA) statement and guidelines [26]. Our criteria included many studies that investigated the efficacy of MRIs to differentiate between the different types of CS especially between low-grade and other advanced highly malignant forms of bone CS. For that, nine databases were searched including PubMed, metaRegister of Controlled Trials (mRCT), Scopus, Google Scholar, WHO Virtual Health Library (VHL), Web of Science (WoS), OpenGrey, Cochrane Library, and EMBASE.

The search strategy was tailored for each database based on three main elements: pathology/histopathology, MRI, and CS. Moreover, the used search term for PubMed was; “Histology” [MeSH],OR Histology [tiab],OR Histological [tiab],OR histopathology* [tiab],OR “pathology”[MeSH Terms] OR pathology[tiab] OR pathological[tiab])) AND ((“Magnetic Resonance Imaging”[MeSH] OR imaging[tiab] OR diagnostic imaging [Subheading] OR mri[tiab] OR DWI[tiab] OR MR scan*[tiab])) AND ((“Chondrosarcoma”[MeSH] OR Chondrosarcoma*[tiab] OR (cartilag*[tiab] AND (tumor*[tiab] OR tumour*[tiab] OR sarcom*[tiab]))). For databases not supporting medical subject heading $(\mathrm{MeSH})$ terms, all possible word combinations were used to cover the possible terminologies. After performing the search strategy, all of the relevant results were exported to one endnote library for the detection and removal of the possible duplicates.

Afterward, all the remaining articles were exported to a standardized excel sheet for future methodology to include the relevant studies. At first, we performed title and abstract screening for a preliminary exclusion of irrelevant studies. Then, full-text download and screening were done to include all the relevant studies that met our criteria. These criteria included studies that investigated the diagnostic ability of MRI in the classification of the different forms of CS before biopsy or preoperatively based on the histopathological findings of these forms and the presence of reported characteristics of the imaging ability in studies that investigated adult patients. All of the screening was done independently by each author and any conflict was resolved by a proper discussion between the three parties to reach a final agreement.

\section{Data extraction and risk of bias}

After reaching the last decision on the final list of the included studies, data were prepared to go through the final step of data extraction to find the relevant outcomes according to the aim of the study. For this purpose, a sample of the included studies was used to construct a standardized extraction sheet that included all of the relevant outcomes including a sheet for the baseline characteristics as the last name of the first author, study year, country, sample size, and age of the included patients. Furthermore, a sheet for the pre-planned included outcome effectiveness of MRIs to differentiate between the different forms of CSs and the characteristics of this imaging. Another sheet was also established to assess the quality of the included studies. The final sheet held all the data extracted which was performed for all the included studies to fit all the relevant information. All of the authors who participated in the data extraction process were blinded from the results of their mates until finishing extraction, which was then followed by a public discussion to reach a final consensus about all of the extracted items. As a part of the extracted data, quality assessment elements were also extracted in the same way as mentioned above. For the assessment of bias, we used the risk of bias in non-randomized studies of interventions (ROBINS-I) tool [27] using the criteria that fit the design of our included studies.

\section{Search results and study characteristics}

Following the whole search process, we retrieved 7,540 records, out of those, 3,408 were duplicates, which left 4,132 studies to be screened. The title and abstract screening phase resulted in 121 papers for full-text screening, of which only 14 were retained. After adding two other studies that were searched manually, we finally included 16 studies for qualitative synthesis (Figure 1). 


\section{Cureus}

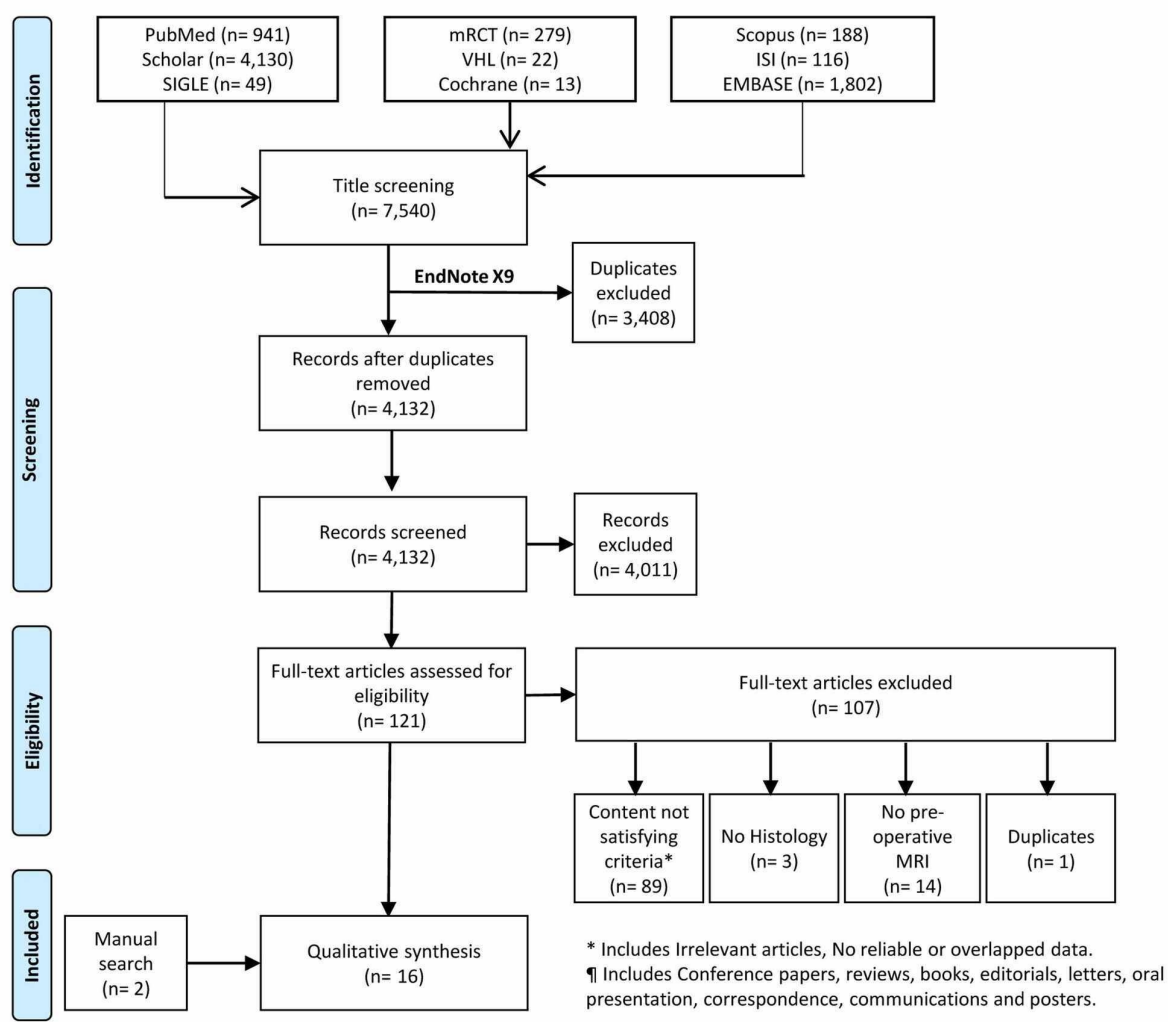

FIGURE 1: PRISMA flowchart of the search and screening process

All the included studies were retrospective published between 2003 and 2020. Moreover, the total sample size was 568 patients with a range of 9 to 179 sample sizes. Among these studies, five studies were conducted in the United Kingdom [28-32], two in the United States [33,34], two in Germany [35,36], two in Italy [37,38], two in China [39,40], one in Korea [41], one in Japan [42], and one in Switzerland [43]. The baseline and summary of the included studies are presented in Table 1.

\begin{tabular}{|c|c|c|c|c|c|c|c|c|c|c|}
\hline \multirow{2}{*}{$\begin{array}{l}\text { Study } \\
\text { Reference }\end{array}$} & \multirow{2}{*}{$\begin{array}{l}\text { Study } \\
\text { Year }\end{array}$} & \multirow{2}{*}{ Country } & \multirow{2}{*}{ Design } & \multirow{2}{*}{$\begin{array}{l}\text { Sample } \\
\text { Size }\end{array}$} & \multicolumn{2}{|l|}{ Study Groups } & \multicolumn{2}{|l|}{ MRI } & \multirow{2}{*}{ Author Conclusion } & \multirow{2}{*}{ Assessed Characteristics } \\
\hline & & & & & Groups & $\mathrm{N}$ & Type & Strength & & \\
\hline $\begin{array}{l}\text { Crim et al. } \\
\text { [33] }\end{array}$ & 2015 & $\begin{array}{l}\text { United } \\
\text { States }\end{array}$ & Retrospective & 53 & $\mathrm{EC}$ and $\mathrm{SC}$ & 32/12 & Conventional & NS & $\begin{array}{l}\text { MRI can detect CS but with } \\
\text { limitations. }\end{array}$ & $\begin{array}{l}\text { Cortical breakthrough, soft-tissue expansion, } \\
\text { scalloping, solid enhancement. }\end{array}$ \\
\hline $\begin{array}{l}\text { Douis et al. } \\
\text { [30] }\end{array}$ & 2014 & $\begin{array}{l}\text { United } \\
\text { Kingdom }\end{array}$ & Retrospective & 179 & $\mathrm{ACT} / \mathrm{CS} 1 / \mathrm{CS} 2 / \mathrm{CS} 3$ & $28 / 79 / 36 / 13 / 23$ & Conventional & NS & $\begin{array}{l}\text { MRI can be used to differentiate } \\
\text { between cS types by bone } \\
\text { expansion, active periostitis, soft- } \\
\text { tissue mass, and tumor length }\end{array}$ & $\begin{array}{l}\text { Bone marrow edema, cortical breakthrough, } \\
\text { soft-tissue expansion, bone expansion, soft- } \\
\text { tissue edema, and periosteal edema. }\end{array}$ \\
\hline $\begin{array}{l}\text { Douis et al. } \\
\text { [28] }\end{array}$ & 2015 & $\begin{array}{l}\text { United } \\
\text { Kingdom }\end{array}$ & Retrospective & 52 & $\mathrm{ACT} / \mathrm{CS} 1 / \mathrm{CS} 2 / \mathrm{CS} 3$ & 5/15/3/2/3 & DWI & 3T & $\begin{array}{l}\text { DWI cannot differentiate between } \\
\text { CS types. }\end{array}$ & Cortical thickening, ADC. \\
\hline $\begin{array}{l}\text { Douis et al. } \\
\text { [29] }\end{array}$ & 2017 & $\begin{array}{l}\text { United } \\
\text { Kingdom }\end{array}$ & Retrospective & 60 & $\mathrm{CS} 1 / \mathrm{CS} 2 / \mathrm{CS} 3$ & 5/3/1/4 & Conventional & $3 \mathrm{~T}$ & $\begin{array}{l}\text { Scalloping is the most sensitive } \\
\text { MRI characteristics. }\end{array}$ & $\begin{array}{l}\text { Entrapped fat, bone marrow edema, cortical } \\
\text { breakthrough, soft-tissue expansion, bone } \\
\text { expansion, scalloping, soft-tissue edema, and } \\
\text { periosteal edema. }\end{array}$ \\
\hline & & & & & $\mathrm{CS} 1 / \mathrm{CS} 2 / \mathrm{CS} 3$ & $15 / 3 / 1 / 4$ & DCE & $3 \mathrm{~T}$ & DCE is not useful in differentiating. & DCE MRI parameters. \\
\hline $\begin{array}{l}\text { Errani et al. } \\
\text { [37] }\end{array}$ & 2017 & Italy & trospective & 89 & EC/ACT & 4/35 & Conventional & $1.5 T$ & $\begin{array}{l}\text { Scalloping and soft-tissue } \\
\text { extension of the most sensitive } \\
\text { MRI characteristics. }\end{array}$ & Soft-tissue expansion, scalloping. \\
\hline Fayad et al. & 2015 & USA & Retrospective & 24 & $\mathrm{CS}_{2 / \mathrm{CS} 3}$ & 1-Jun & Sonventiona & $1.5 T$ & $\begin{array}{l}\text { Scalloping and soft-tissue } \\
\text { extension of the most sensitive } \\
\text { MRI characteristics. }\end{array}$ & $\begin{array}{l}\text { Soft-tissue expansion, solid enhancement, } \\
\text { soft-tissue edema, and periosteal edema. }\end{array}$ \\
\hline
\end{tabular}




\section{Cureus}

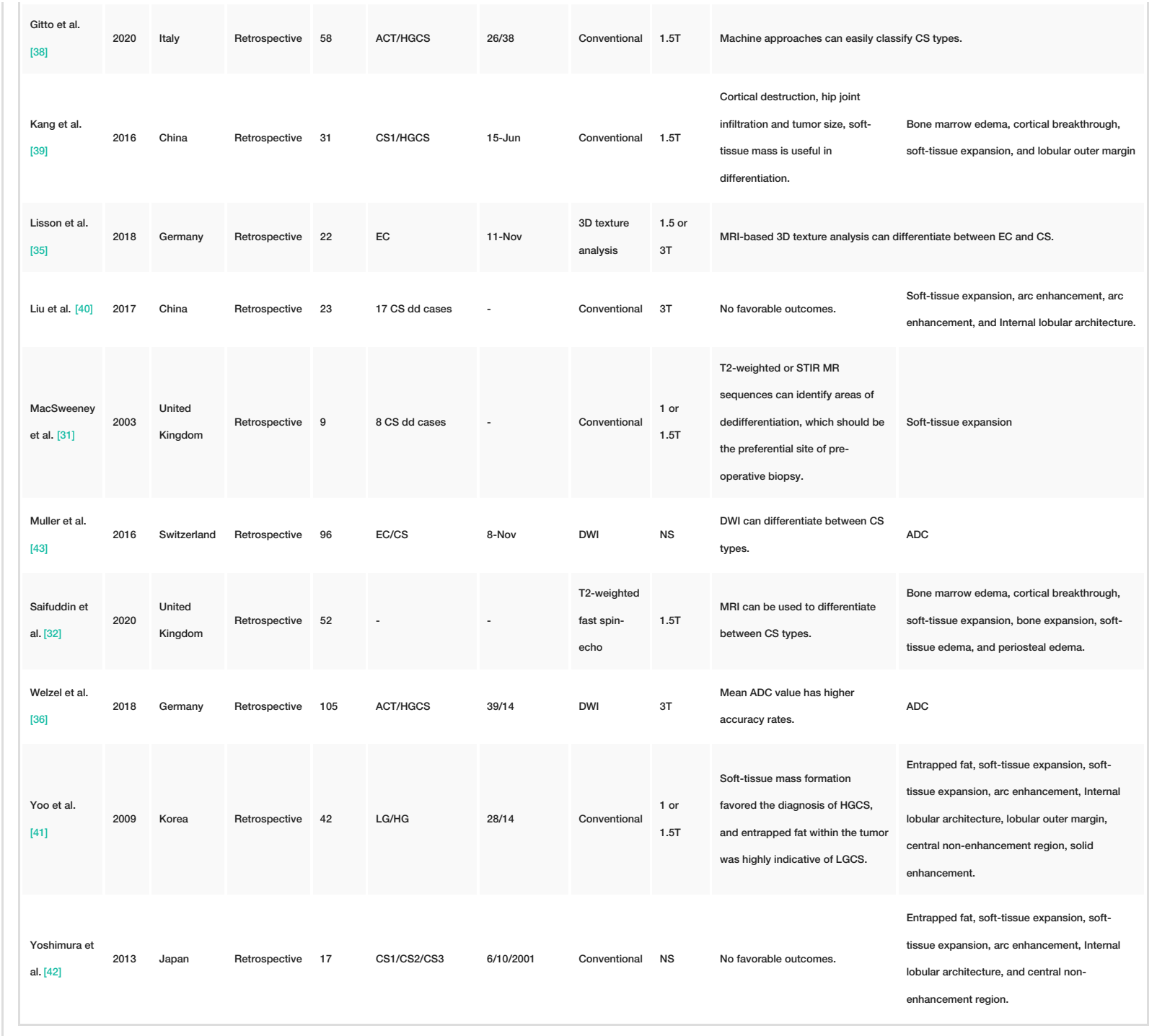

\section{TABLE 1: Baseline characteristics of the included studies}

ACT: atypical cartilaginous tumors, ADC: apparent diffusion coefficient, CS: chondrosarcoma, DCE: dynamic contrast-enhanced, DWI: diffusionweighted imaging, EC: enchondroma, HGCS: high-grade chondrosarcomas, HG: high grade, LG: low Grade, MRI: magnetic resonance imaging.

\section{Quality assessment results}

The overall quality of the included study varied hugely. According to the risk-assessment results, we found that seven studies [30-32,34,39-41] had a low risk of bias while only two were classified as high-risk studies $[29,36]$. In terms of confounding bias, only two studies $[34,42]$ had a moderate risk of bias while none of the studies had a high risk. Missing data were found to cause a high risk of bias in two of the included studies $[31,33]$ (Appendices).

\section{Accuracy of MRIs in diagnosis and detecting characteristics}

Among all the included studies, only seven studies $[29,30,32,33,35,36,42]$ reported the efficacy and overall accuracy in the diagnosis and differentiation of CS. Saifuddin et al. reported an overall accuracy of $92 \%$ in a pre-biopsy-two-reader approach with a sensitivity of 91\% [32]. Meanwhile, Yoshimura et al. reported high sensitivity rates in terms of entrapped fat, ring and arc enhancement, and soft-tissue mass formation characteristics [42]. However, the authors found that computed tomography and plain radiography were more sensitive in the detection of calcification, scalloping, and cortical penetration. Therefore, the authors suggested the combined utilization of both modalities for better accuracy. Furthermore, Welzel et al. reported high sensitivity and specificity rates for MRI in terms of apparent diffusion coefficient (ADC) values between chondroma and CS [36]. Lisson et al. reported an overall accuracy of $86 \%$ and $82 \%$ for the detection of kurtosis and entropy that are essential for discrimination between chondroma and CS [35]. Similarly, Douis et al. reported a positive predictive value (PPV) of $100 \%$ for the detection of cortical destruction and soft tissue masses, and 70\% only for bone expansion [29]. Douis et al. reported an overall 
accuracy of $95.6 \%$ for MRI diagnostic ability [30]. Lastly, Crim et al. reported a 14\% false-positive rate of MRI in diagnosing malignancy, which was much higher than the rate reported with radiography (3.1\%) [33].

\section{MRI reported characteristics}

Various MRI characteristics have been identified and are discussed as follows. Entrapped fat was reported by three of the included studies [29,41,42]. Among these studies, Yoo et al. and Douis et al. reported that the presence of entrapped fat or fatty pools was significantly observed in ACTs more than HGCS $(\mathrm{P}<0.01)[29,41]$. In the same context, Yoshimura et al. found that the number of entrapped fat observations was more in the ACT group (26/28) than the HGCS one (1/14), with a reported PPV of $90 \%$ in this point [42].

\section{Characteristic detection of edema}

Regarding bone marrow edema, it was reported by only three studies [29,30,39]. Among these studies, Kang et al. reported that the presence of peritumoral edema was observed in all of the patients in the ACT and HGCS groups, and therefore, no significance was found [39]. In the same context, Douis et al. [30] in their study in 2014, reported statistical significance between the two groups while in their study that was conducted in 2018 [29], a statistical significance was found in the presence of bone marrow edema among all chondroma tumors. However, a higher rate was noticed among the HGCS patients (6/8) versus ACT patients (7/15). Similarly, the presence of soft-tissue and periosteal edema was compared between ACT and HGCS by two of the included studies [29,30]. Both studies found a significant relationship between the two groups; however, Douis et al. [29] results might have been influenced by the heterogeneity of the results between the different groups of chondromas that were included. Lastly, Fayad et al. reported a high rate in the presence of soft-tissue edema and periosteal edema; however, the authors included only patients with grade 2-3 CS with no comparison between them and ACT [34].

\section{Characteristics detection of expansion}

The bone expansion reported by Douis et al. in 2014 and 2015 reported that a higher rate of bone expansion was significantly associated with HGCS than ACT $[28,30]$. On the other hand, soft-tissue expansion was reported by 10 studies [29-31,33,34,37,39-42]. Among these, only five of them [29,30,33,37,39,41,42] compared the significance of the presence of the characteristic on MRIs while Crim et al. [33] and Errani et al. [37] reported pure rates only in ACT patients without comparing them with rates of $25 \%$ and $23.5 \%$, respectively. Meanwhile, Fayad et al. [34], Macsweeney et al. [31], and Liu et al. [40] reported that almost all of their HGCS population were observed to have soft-tissue expansion on MRIs. Moreover, among the studies that compared ACT and HGCS, significantly higher rates were associated with the HGCS group in all of them with scalloping being reported as one of the characteristics. Nonetheless, Douis et al. [28], reported that all of their patients had developed scalloping. However, Crim et al. [33] and Errani et al. [37] found smaller rates in the ACT group (25\% and $52.9 \%$, respectively) with no reported outcomes regarding the HGCS.

\section{Characteristics related to the cortex and overall architecture}

The lobular internal architecture was significantly present in the ACT group according to Yoshimura et al. [42] and Yoo et al. [41]. In HGCS, two studies [40,42] reported a high rate of detection; however, Yoo et al. [41] reported the lowest rate, which was significant when compared to the ACT group $(\mathrm{P}<0.01)$. The lobular outer margin was observed in almost all of the patients in the ACT and HGCS groups [39,41]. However, Yoo et al. [41] found a lower rate in the HGCS group (71\%) with an estimation associated differences in the incidence between the two groups $(\mathrm{P}<0.05)$. A breakthrough in the cortex was also present more significantly in the HGCS group than the ACT one as reported by four studies [29,30,39,41] compared to Crim et al. [33] where they reported a rate of $25 \%$ in their small ACT population with no comparison. In the same context, Yoo et al. [41] found that the destruction of the cortex was significantly observed in HGCS patients than with ACT $(\mathrm{P}<0.01)$. Additionally, Douis et al. [30] reported that none of the ACT patients had cortical thickening while a rate of $22 \%$ of the HGCS population developed these characteristics.

\section{Characteristics related to enhancements}

Regarding the comparison between the ring and arc enhancements between the ACT and HGCS groups. Yoo et al. outlined that $100 \%$ of his population's MRI results outlined enhancements while a significantly higher rate was observed in the ACT group than the HGCS where no enhancements were reported [41]. Another two studies $[34,40]$ reported enhancements with the HGCS group reinforcing the results outlined by Yoo et al.

[41]. However, the two studies did not compare their results to the HGCS group. Solid enhancement was also reported by three studies $[33,34,41]$ with Yoo et al. study reporting a better enhancement finding in the HGCS group. Additionally, Fayad et al. [34] and Crim et al. [33] described moderate enhancement rates in the HGCS and ACT groups. Lastly, a central area of non-enhancement was significantly observed in the HGCS group than the ACT one $[41,42]$.

\section{Other reported outcomes}

Assessment of tumor size was reported to be significantly larger in HGCS than ACT by Kang et al. [39] while 
Douis et al. [29] found no significant association. Most of the included studies [29-31,33,34,37,39-42] used the conventional MRI approach to assess their patients while another three studies $[28,36,43]$ used the diffusion-weighted imaging (DWI) MRI approach which was mainly conducted to assess ADC. Moreover, Douis et al. [28] found no significance in ADC while Welzel et al. [36] reported that ADC was higher in grade 1 than grade 2 ACT, meanwhile, Müller et al. [43] reported high values with grade 1 but did not have any comparison. Lisson et al. [35] observed another two characteristics including kurtosis and entropy using contrast-enhanced and non-contrast T1-weighted MRI images by 3D analysis. However, the authors did not make a comparison between ACT and HGCS but did compare between EC and grade $1 \mathrm{CS}$. Douis et al. also used another approach and found no significance between the ACT and HGCS groups according to the dynamic contrast-enhanced (DCE) MRI findings [29]. Gitto et al. used an unenhanced MRI to compare the radiologist-based and machine-based evaluation of ACT and HGCS and showed that the latter could add to the diagnosis of both lesions, but with no statistical significance [38].

Limitations to our study include the relatively smaller sample size of the included studies. Moreover, we observed heterogeneity between the reported MRI characteristics of the included studies with no clear and defined outcomes between all of them. The definition of MRI accuracy was hugely variable among the studies which may have made it difficult for comparison.

\section{Conclusions}

The overall reported accuracy of MRI as a differentiating tool between ACT and HGCS was generally acceptable and even high in some detected characteristics. However, it has been reported that the combined use of MRI and radiography will result in more accuracy. Additionally, the main characteristics that could be detected by MRIs include peritumor edema, entrapped fat, cortical damage, and expansion of the extraosseous soft tissue. These can effectively differentiate between ACT and HGCS according to the included studies with further studies needed on a larger sample-sized population.

\section{Appendices}

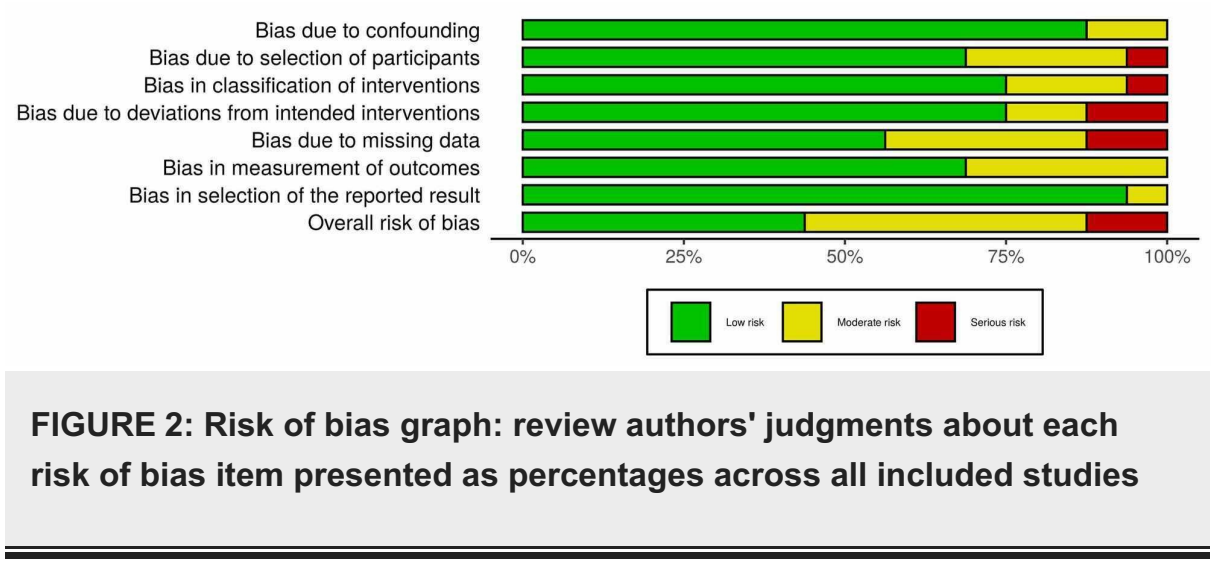




\section{Cureus}

\begin{tabular}{|c|c|c|c|c|c|c|c|c|}
\hline & & & & Risk of $\mathrm{k}$ & domains & & & \\
\hline & D & & D3 & $\mathrm{D} 4$ & D5 & D6 & D7 & Overall \\
\hline Crim et al. 2015 & & & & & & & & -) \\
\hline Douis et al. 2014 & & & & & & & & 1 \\
\hline Douis et al. 2015 & & & & & & & & 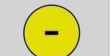 \\
\hline Douis et al. 2018 & & & & & & & & \\
\hline Errani et al. 2017 & & & & & & & & ) \\
\hline Fayad et al. 2015 & & & & & & & & 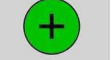 \\
\hline Gitto et al. 2020 & & & & & & & & \\
\hline Kang et al. 2016 & & & & & & & & 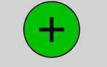 \\
\hline Lisson et al. 2017 & & & & & & & & ) \\
\hline Liu et al. 2017 & & & & & & & & \\
\hline MacSweeney et al. 2003 & & & & & & & & 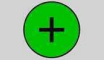 \\
\hline Muller et al. 2016 & & & & & & & & \\
\hline Saifuddin et al. 2020 & & & & & & & & 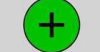 \\
\hline Welzel et al. 2018 & & & & & & & & \\
\hline Yoo et al. 2009 & & & & & & & & + \\
\hline Yoshimura et al. 2013 & & & & 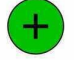 & 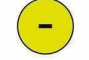 & & & ) \\
\hline & 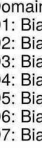 & & & & & & & $\begin{array}{l}\text { Judgement } \\
\text { Serious } \\
\text { Moderate } \\
\text { () Low }\end{array}$ \\
\hline
\end{tabular}

FIGURE 3: Risk of bias summary: review authors' judgments about each risk of bias item for each included study

\section{Additional Information}

\section{Disclosures}

Conflicts of interest: In compliance with the ICMJE uniform disclosure form, all authors declare the following: Payment/services info: All authors have declared that no financial support was received from any organization for the submitted work. Financial relationships: All authors have declared that they have no financial relationships at present or within the previous three years with any organizations that might have an interest in the submitted work. Other relationships: All authors have declared that there are no other relationships or activities that could appear to have influenced the submitted work.

\section{References}

1. Rosenberg AE, Nielsen GP, Keel SB, Renard LG, Fitzek MM, Munzenrider JE, Liebsch NJ: Chondrosarcoma of the base of the skull: a clinicopathologic study of 200 cases with emphasis on its distinction from chordoma. 
Am J Surg Pathol. 1999, 23:1370-1378. 10.1097/00000478-199911000-00007

2. Lichtenstein L, Jaffe HL: Chondrosarcoma of bone. Am J Pathol. 1943, 19:553-589.

3. Gelderblom H, Hogendoorn PC, Dijkstra SD, van Rijswijk CS, Krol AD, Taminiau AH, Bovée JV: The clinical approach towards chondrosarcoma. Oncologist. 2008, 13:320-329. 10.1634/theoncologist.2007-0237

4. Giuffrida AY, Burgueno JE, Koniaris LG, Gutierrez JC, Duncan R, Scully SP: Chondrosarcoma in the United States (1973 to 2003): an analysis of 2890 cases from the SEER database. J Bone Joint Surg Am. 2009, 91:1063-1072. 10.2106/JBJS.H.00416

5. Henderson ED, Dahlin DC: Chondrosarcoma of bone - a study of two hundred and eighty-eight cases . J Bone Joint Surg Am. 1963, 45:1450-1458.

6. Mirra JM, Gold R, Downs J, Eckhardt JJ: A new histologic approach to the differentiation of enchondroma and chondrosarcoma of the bones: a clinicopathologic analysis of 51 cases. Clin Orthop Relat Res. 1985, 201:214-237.

7. Deckers C, Schreuder BH, Hannink G, de Rooy JW, van der Geest IC: Radiologic follow-up of untreated enchondroma and atypical cartilaginous tumors in the long bones. J Surg Oncol. 2016, 114:987-991. 10.1002/jso.24465

8. Chen W, Zhu H, Zhang L, et al.: Primary bone malignancy: effective treatment with high-intensity focused ultrasound ablation. Radiology. 2010, 255:967-978. 10.1148/radiol.10090374

9. Grimer RJ, Carter SR, Tillman RM, Mangham DC, Abudu A, Fiorenza F: Chondrosarcoma of bone. J Bone Joint Surg Am. 2000, 82:1203-1204. 10.2106/00004623-200008000-00037

10. Gay E, Sekhar LN, Rubinstein E, Wright DC, Sen C, Janecka IP, Snyderman CH: Chordomas and chondrosarcomas of the cranial base: results and follow-up of 60 patients. Neurosurgery. 1995, 36:887-896. 10.1227/00006123-199505000-00001

11. Dahlin DC, Beabout JW: Dedifferentiation of low-grade chondrosarcomas. Cancer. 1971, 28:461-466. 10.1002/1097-0142(197108)28:2<461::AID-CNCR2820280227>3.0.CO;2-U

12. Mercuri M, Picci P, Campanacci L, Rulli E: Dedifferentiated chondrosarcoma. Skeletal Radiol. 1995, 24:409416. 10.1007/bf00941235

13. Frassica FJ, Unni KK, Beabout JW, Sim FH: Dedifferentiated chondrosarcoma. A report of the clinicopathological features and treatment of seventy-eight cases. J Bone Joint Surg Am. 1986, 68:11971205.

14. de Lange EE, Pope TL Jr, Fechner RE: Dedifferentiated chondrosarcoma: radiographic features . Radiology. 1986, 161:489-492. 10.1148/radiology.161.2.3763920

15. Evans HL, Ayala AG, Romsdahl MM: Prognostic factors in chondrosarcoma of bone: a clinicopathologic analysis with emphasis on histologic grading. Cancer. 1977, 40:818-831. 10.1002/10970142(197708)40:2<818::AID-CNCR2820400234>3.0.CO;2-B

16. Fiorenza F, Abudu A, Grimer RJ, et al.: Risk factors for survival and local control in chondrosarcoma of bone . J Bone Joint Surg Br. 2002, 84:93-99. 10.1302/0301-620x.84b1.11942

17. Söderström M, Ekfors TO, Böhling TO, Teppo LH, Vuorio EI, Aro HT: No improvement in the overall survival of 194 patients with chondrosarcoma in Finland in 1971-1990. Acta Orthop Scand. 2003, 74:344-350. 10.1080/00016470310014292

18. Pritchard DJ, Lunke RJ, Taylor WF, Dahlin DC, Medley BE: Chondrosarcoma: a clinicopathologic and statistical analysis. Cancer. 1980, 45:149-157. 10.1002/1097-0142(19800101)45:1<149::AIDCNCR2820450125>3.0.CO;2-A

19. Weber KL, Raymond AK: Low-grade/dedifferentiated/high-grade chondrosarcoma: a case of histological and biological progression. Iowa Orthop J. 2002, 22:75-80.

20. Walden MJ, Murphey MD, Vidal JA: Incidental enchondromas of the knee. AJR Am J Roentgenol. 2008, 190:1611-1615. 10.2214/AJR.07.2796

21. Hong ED, Carrino JA, Weber KL, Fayad LM: Prevalence of shoulder enchondromas on routine MR imaging . Clin Imaging. 2011, 35:378-384. 10.1016/j.clinimag.2010.10.012

22. Brien EW, Mirra JM, Kerr R: Benign and malignant cartilage tumors of bone and joint: Their anatomic and theoretical basis with an emphasis on radiology, pathology and clinical biology - I: the intramedullary cartilage tumors. Skeletal Radiol. 1997, 26:325-353. 10.1007/s002560050246

23. Milgram JW: The origins of osteochondromas and enchondromas. A histopathologic study . Clin Orthop Relat Res. 1983, 174:264-284.

24. Murphey MD, Flemming DJ, Boyea SR, Bojescul JA, Sweet DE, Temple HT: Enchondroma versus chondrosarcoma in the appendicular skeleton: differentiating features. Radiographics. 1998, 18:1213-1237. 10.1148/radiographics.18.5.9747616

25. Deckers C, Steyvers MJ, Hannink G, Schreuder HWB, de Rooy JWJ, Van Der Geest ICM: Can MRI differentiate between atypical cartilaginous tumors and high-grade chondrosarcoma? A systematic review. Acta Orthop. 2020, 91:471-478. 10.1080/17453674.2020.1763717

26. Moher D, Liberati A, Tetzlaff J, Altman DG: Preferred reporting items for systematic reviews and metaanalyses: the PRISMA statement. PLoS Med. 2009, 6:e1000097. 10.1371/journal.pmed.1000097

27. Sterne JA, Hernán MA, Reeves BC, et al.: ROBINS-I: a tool for assessing risk of bias in non-randomised studies of interventions. BMJ. 2016, 355:i4919. 10.1136/bmj.i4919

28. Douis H, Jeys L, Grimer R, Vaiyapuri S, Davies AM: Is there a role for diffusion-weighted MRI (DWI) in the diagnosis of central cartilage tumors?. Skeletal Radiol. 2015, 44:963-969. 10.1007/s00256-015-2123-7

29. Douis H, Parry M, Sumathi V, Davies AM: What are the differentiating clinical and MRI-features of enchondromas from low-grade chondrosarcomas?. Eur Radiol. 2017, 28:398-409. 10.1007/s00330-017-49470

30. Douis H, Singh L, Saifuddin A: MRI differentiation of low-grade from high-grade appendicular chondrosarcoma. Eur Radiol. 2014, 24:232-240. 10.1007/s00330-013-3003-y

31. MacSweeney F, Darby A, Saifuddin A: Dedifferentiated chondrosarcoma of the appendicular skeleton: MRIpathological correlation. Skeletal Radiol. 2003, 32:671-678. 10.1007/s00256-003-0706-1

32. Saifuddin A, Oliveira I, Singla N, Chavda A, Khoo M, O'Donnell P: The importance of MRI review following the diagnosis of atypical cartilaginous tumour using image-guided needle biopsy [PREPRINT]. Skeletal 
Radiol. 2020, 10.1007/s00256-020-03578-7

33. Crim J, Schmidt R, Layfield L, Hanrahan C, Manaster BJ: Can imaging criteria distinguish enchondroma from grade 1 chondrosarcoma?. Eur J Radiol. 2015, 84:2222-2230. 10.1016/j.ejrad.2015.06.033

34. Fayad LM, Ahlawat S, Khan MS, McCarthy E: Chondrosarcomas of the hands and feet: a case series and systematic review of the literature. Eur J Radiol. 2015, 84:2004-2012. 10.1016/j.ejrad.2015.06.026

35. Lisson CS, Lisson CG, Flosdorf K, et al.: Diagnostic value of MRI-based 3D texture analysis for tissue characterisation and discrimination of low-grade chondrosarcoma from enchondroma: a pilot study. Eur Radiol. 2018, 28:468-477. 10.1007/s00330-017-5014-6

36. Welzel T, Meyerhof E, Uhl M, Huang K, von Deimling A, Herfarth K, Debus J: Diagnostic accuracy of DW MR imaging in the differentiation of chordomas and chondrosarcomas of the skull base: a 3.0-T MRI study of 105 cases. Eur J Radiol. 2018, 105:119-124. 10.1016/j.ejrad.2018.05.026

37. Errani C, Tsukamoto S, Ciani G, et al.: Risk factors for local recurrence from atypical cartilaginous tumour and enchondroma of the long bones. Eur J Orthop Surg Traumatol. 2017, 27:805-811. 10.1007/s00590-0171970-4

38. Gitto S, Cuocolo R, Albano D, et al.: MRI radiomics-based machine-learning classification of bone chondrosarcoma. Eur J Radiol. 2020, 128:109043. 10.1016/j.ejrad.2020.109043

39. Kang Y, Yuan W, Ding X, Wang G: Chondrosarcoma of the para-acetabulum: correlation of imaging features with histopathological grade. Radiol Med. 2016, 121:897-904. 10.1007/s11547-016-0673-y

40. Liu C, Xi Y, Li M, Jiao Q, Zhang H, Yang Q, Yao W: Dedifferentiated chondrosarcoma: Radiological features, prognostic factors and survival statistics in 23 patients. PLoS One. 2017, 12:e0173665. 10.1371/journal.pone.0173665

41. Yoo HJ, Hong SH, Choi JY, Moon KC, Kim HS, Choi JA, Kang HS: Differentiating high-grade from low-grade chondrosarcoma with MR imaging. Eur Radiol. 2009, 19:3008-3014. 10.1007/s00330-009-1493-4

42. Yoshimura Y, Isobe K, Arai H, Aoki K, Kito M, Kato H: Preoperative radiographic and histopathologic evaluation of central chondrosarcoma. Arch Orthop Trauma Surg. 2013, 133:1225-1231. 10.1007/s00402013-1800-z

43. Müller U, Kubik-Huch RA, Ares C, Hug EB, Löw R, Valavanis A, Ahlhelm FJ: Is there a role for conventional MRI and MR diffusion-weighted imaging for distinction of skull base chordoma and chondrosarcoma?. Acta Radiol. 2016, $57: 225-232$. 10.1177/0284185115574156 